\title{
Algumas considerações para elevar o crescimento da economia brasileira
}

\author{
Rudinei Toneto Junior* \\ Luciano Nakabashi* \\ Guilherme Byrro Lopes ${ }^{* * *}$
}

\begin{abstract}
Resumo: O objetivo do trabalho é apontar alguns elementos que determinam o crescimento da economia brasileira, com vistas a possibilitar sua aceleração. A retomada do crescimento sustentável da economia em patamares mais elevados passa, necessariamente, por avanços na acumulação de capital físico, capital humano e produtividade. Para que isso seja possível, é preciso recuperar a capacidade de investimento do setor público, com redução da carga tributária, para que o setor privado também possa ser estimulado. A participação do setor industrial no PIB parece ser relevante para melhorar o desempenho da economia brasileira pelo seu maior dinamismo.
\end{abstract}

Palavras chaves: aceleração do crescimento; investimento público; carga tributária; setor industrial.

Classificação JEL: E22; E23; E60

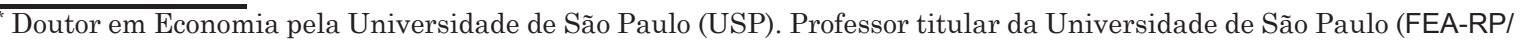
USP). Endereço eletrônico: rtoneto@usp.br

** Doutor em Economia pela Universidade Federal de Minas Gerais (UFMG). Professor da Universidade de São Paulo (FEA-RP/USP). Endereço eletrônico: luciano.nakabashi@gmail.com

*** Graduado em Economia pela Universidade de São Paulo (USP). Mestrando da Universidade de São Paulo (FEA-RP/ USP). Endereço eletrônico: gui.byrro@gmail.com
} 


\section{Introdução}

O objetivo do trabalho é apontar alguns elementos que determinam o crescimento da economia brasileira, com vistas a possibilitar sua aceleração, inclusive apontando a importância da sua estrutura produtiva.

No período 1980/2011 o crescimento médio brasileiro foi da ordem de $2,61 \%$ a.a. e o do PIB per capita em torno de $1 \%$ a.a., sendo o pior desempenho na década de 80 quando houve queda do PIB per capita (-0,47\% a.a.). Esse quadro começou a ser ligeiramente alterado nos anos 2000, com destaque para o período 2004/08 em que o crescimento médio foi de 4,82\%a.a., resultando em um aumento do PIB per capita da ordem de 3,6\% a.a.. Essa situação se reverteu com a crise econômica internacional que trouxe a média de aumento do PIB para $3,3 \%$ no triênio $2009 / 11$.

Durante o período 1947-80, o crescimento médio do PIB brasileiro foi da ordem de 7,5\%a.a. e o do PIB per capita foi de 4,6\% a.a.. Essa fase foi caracterizada pela intensificação do processo de industrialização brasileiro, com forte expansão da indústria de transformação e significativa urbanização.

Deve-se destacar as maiores taxas de crescimento alcançadas no período 1968/80, que pode ser decomposto entre a fase do Milagre Econômico Brasileiro (1968/73) e a fase de implantação do II Plano Nacional de Desenvolvimento (IIPND - 1974/79). Nesse período, verificaram-se alguns fatos marcantes:

(i) Forte ampliação da participação da indústria de transformação, com fortalecimento dos setores de bens de capital e de bens intermediários, em especial na segunda metade dos anos 70 ;

(ii) Elevação significativa das taxas de investimento, com grande importância do investimento público, em especial nos setores de infraestrutura (transportes, energia, telecomunicações, saneamento básico, entre outros);

(iii) Ganhos de competitividade da indústria nacional, com aumento da participação de manufaturados na pauta exportadora, e diversificação das exportações;

(iv) Forte crescimento do sistema financeiro e do processo de intermediação de recursos após a consolidação do sistema financeiro, criação do Sistema Financeiro da Habitação, bancos de investimento, crédito ao consumidor e fortalecimento do BNDES;

(v) Criação e fortalecimento de instituições voltadas para a pesquisa e desenvolvimento tecnológico: Embrapa, FINEP, sistema de pós-graduação, Centro Tecnológico Aeroespacial, entre outros; 
(vi) Forte ampliação do emprego e aumento da PEA, em função do processo de urbanização, com elevação da produtividade dos trabalhadores; entre outros fatores.

A partir da crise da dívida externa e da crise fiscal do estado houve uma profunda reversão nas taxas de crescimento. A profunda instabilidade econômica, com forte elevação da inflação ao longo dos anos de 1980 e na primeira metade dos 90 , restringiu a capacidade de crescimento do país. A retração da poupança pública limitou fortemente a capacidade de investimento do governo. $\mathrm{O}$ investimento como um todo sofreu significativa queda. A adoção de diversos planos econômicos e medidas emergenciais, pela necessidade de se ajustar ao cenário externo e combater a inflação, deterioraram o ambiente de negócios e provocaram perda de eficiência.

Custos mais elevados e baixo dinamismo econômico sacrificaram diversos setores econômicos, com destaque para diversos setores industriais. Mesmo com a estabilização, manteve-se baixa a capacidade de crescimento: taxas de juros elevada, câmbio valorizado, carga tributária crescente, entre outros fatores travaram o crescimento. Assim, a instabilidade econômica e a crise da divida externa e fiscal dos anos 80 reverteram a trajetória de crescimento que se manteve baixa apesar da estabilização a partir de meados dos 90 .

Mas, deve-se destacar que o bom desempenho do país, ao longo do processo de industrialização, sinaliza possível voltarmos a ter taxas de crescimento mais elevadas. Deve-se buscar identificar quais fatores impulsionaram o crescimento naquele período, verificar a possibilidade de se retomar algum dos seus aspectos determinantes e identificar quais os principais entraves que têm impedido a retomada do crescimento de forma sustentável desde os anos de 1980, principalmente, aqueles entraves que se mantiveram e se reforçaram após a estabilização.

Outro ponto a ser destacado é o forte dinamismo das chamadas economias emergentes nos últimos anos, com destaque para países como a China e a Índia. Esse grupo tem ampliado de forma significativa sua participação mundial e suas perspectivas de crescimento são muito mais favoráveis que as das economias desenvolvidas. Entre essas economias, o Brasil não tem se colocado como dos mais dinâmicos. A tabela seguinte mostra o desempenho comparado entre nações emergentes no período 1995-2008, que contempla a fase iniciada com a estabilização monetária no Brasil até a chegada da crise internacional. 
Tabela 1 - TAXA MÉDIA DE CRESCIMENTO DO PIB PARA O PERÍODO DE 1995

\begin{tabular}{lc}
\multicolumn{2}{c}{ A 2008 (\%) } \\
\hline Países Selecionados & $\%$ \\
\hline China & 9,7 \\
Coréia do Sul & 4,8 \\
Singapura & 5,7 \\
Índia & 6,9 \\
Vietnã & 7,5 \\
Chile & 4,7 \\
Turquia & 4,6 \\
Brasil Fonte: Banco Mundial, apud DEPECON- \\
\multicolumn{2}{c}{ FIESP (2010a) }
\end{tabular}

Assim, seja com base nos casos de sucesso internacional ou seja pela própria experiência brasileira, acredita-se ser possível sustentar taxas mais elevadas de crescimento, para permitir o aumento da renda média dos brasileiros a níveis próximos ao dos países desenvolvidos.

Além dessa introdução, na seção seguinte é apresentada uma análise descritiva da evolução econômica brasileira. Por fỉm, são apresentadas as conclusões do trabalho.

\section{0 crescimento econômico brasileiro: análise descritiva}

Ao longo do século XX, o Brasil foi um dos países que apresentou melhor desempenho na economia mundial. O crescimento médio do PIB entre $1901 \mathrm{e}$ 2000 foi da ordem de 5,0\% a.a. e do PIB per capita de 2,65\% a.a.. Esse processo foi relativamente intenso entre a Segunda Guerra Mundial e o início dos anos de 1980, com taxas médias de crescimento do PIB da ordem de 7,5\%a., o que resultou em um aumento médio do PIB per capita da ordem de 4,6\%a.a.. Com isso, entre os anos 1948 e 1980, o PIB per capita mais do que quadruplicou, passando de valores próximos a US $\$ 2.000,00$ para valores superiores a US\$8.000,00 ${ }^{1}$. Desde então, a situação sofreu uma forte inflexão, o crescimento médio do PIB entre 1980 e 2011 foi de 2,6\%a.a. e do PIB per capita da ordem de 1\%a.a..

Assim, enquanto no período anterior o país precisava de aproximadamente 15 anos para dobrar o seu PIB per capita, pelo desempenho das últimas décadas o país precisa de 70 anos para alcanças este feito. Ou seja, na fase anterior o trabalhador via sua renda média quadruplicar ao longo de sua vida ativa, na dinâmica recente precisamos de 2 gerações para conseguir dobrar a renda média. A questão chave é compreender o que possibilitou um crescimento elevado durante as mais de três décadas seguintes à Segunda Guerra Mundial e o que provocou a queda tão acentuada nas três décadas, a partir de 1980.

Para identificarmos os fatores determinantes desse desempenho,

$\overline{1 \text { Ver Ipeadata PIB }}$ per capita US\$ valores de 2011. 
deve-se destacar que a evolução da renda dos indivíduos está diretamente relacionada à sua produtividade, isto é, a quantidade de produto que gera por unidade de tempo. Esta depende de uma série de fatores: a sua qualificação, a quantidade e a qualidade dos equipamentos e instrumentos de trabalho de que dispõe, do tempo que dedica à atividade produtiva, da intensidade com que trabalha, entre outros fatores. De uma forma geral, pode-se dizer que quanto maior a qualificação do trabalhador, maior a quantidade de capital que dispõe (equipamentos e instrumentos), maior o incentivo ao trabalho, menor o tempo gasto em transações ou atividades não-produtivas, melhor a saúde, maior será a sua produtividade e sua renda. Disto podemos definir quais são os fatores determinantes do crescimento do PIB de um país:

(i) Crescimento da força de trabalho (crescimento demográfico, aumento da taxa de participação, melhora das condições de saúde - afeta produtividade e horas de trabalho, entre outros);

(ii) Aumento do estoque de capital (equipamentos e instrumentos de trabalho);

(iii) Aumento da qualificação dos trabalhadores (capital humano: conhecimento e capacitação);

(iv) Aumento da produtividade dos fatores (novas tecnologias, aumento da eficiência, redução de desperdícios, entre outros).

Em termos de PIB per capita, os fatores são os mesmos, mas cada uma dessas variáveis deve ser relativizada com o crescimento demográfico. Dessa forma, o PIB per capta evolui de acordo com:

(i) o crescimento da força de trabalho relativamente à população (PEA em relação à população total, ou aumento das horas trabalhadas para uma dada população);

(ii) o aumento do estoque de capital per capita;

(iii) a acumulação de capital humano per capita;

(iv) o aumento da produtividade.

Se considerarmos que existe limite à expansão dos dois primeiros fatores e que a contribuição dos mesmos pode perder a eficácia quando eles já se encontram em níveis elevados, conclui-se que os principais fatores a determinar a melhoria das condições de vida, no longo prazo, são o capital humano e a produtividade. 
Com base nessas considerações, pode-se buscar analisar o desempenho brasileiro ao longo das últimas décadas, para identificar quais fatores impulsionaram as taxas elevadas de crescimento até 1980 e quais provocaram sua reversão.

O gráfico 1 apresenta as taxas anuais de crescimento do PIB e do PIB da indústria de transformação no período 1948/2011. Como já destacado, o PIB cresceu a uma taxa média da ordem de 7,5\%a.a. no período 1948/80, sendo que de 1948 a 1968 a média foi de 6,5\% e de 1968 a 1980 foi de 9\%a.a.. Esse desempenho se deu com a intensificação do processo de industrialização no país. Nesse período, a indústria de transformação cresceu a uma taxa média de 8,75\%a.a, sendo que entre os anos 1948 e 1968 a média foi de 8,05\% e nos anos seguintes até 1980 a média foi de 9,83\%. Nota-se que, em todo o período, a taxa de crescimento industrial foi maior do que a do PIB, fazendo com que a indústria de transformação aumentasse sua participação no PIB.

Gráfico 1 - Evolução do PIB e PIB indústria Transformação - 1948/2011

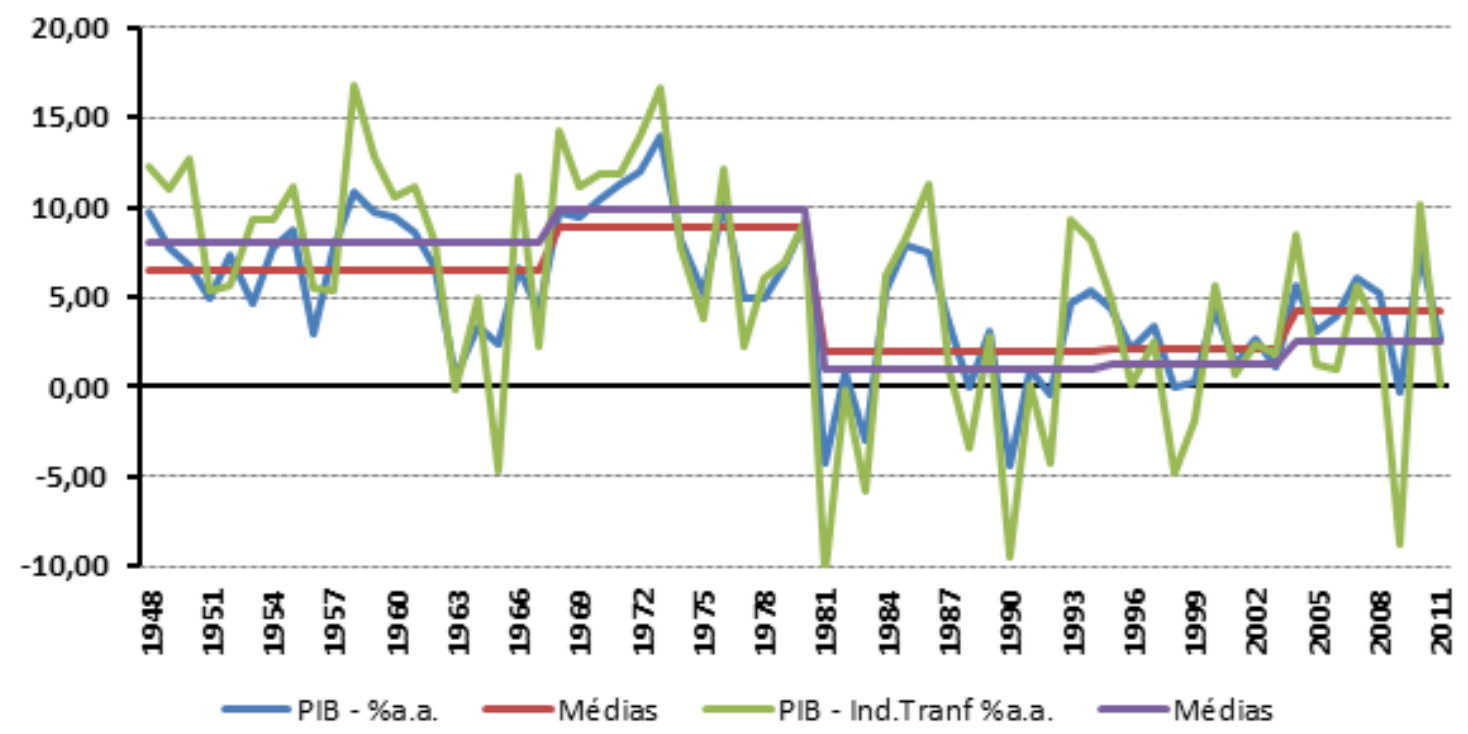

Nos anos de 1970, em que a taxa de crescimento do PIB industrial foi maior, houve uma grande expansão em todos os segmentos da indústria, com destaque para o setor de bens de consumo duráveis nos primeiros anos e os bens de capital e bens intermediários na segunda fase. A taxa de investimento se elevou de forma acentuada, superando por vários anos seguidos o patamar dos $20 \%$ do PIB como veremos adiante.

O gráfico 1 fornece indícios de que a indústria foi relevante no processo de aceleração do crescimento nos anos de 1960 e 1970, e na posterior desaceleração. Uma razão é que esse setor é mais dinâmico em termos de produtividade e inovação, além de possuir maior nível de encadeamentos com outros segmentos e setores. O problema é que a perda de participação da indústria foi compensada por ganho de participação no setor de serviços, em segmentos de baixa produtividade e pouco dinâmicos (CRUZ ET AL., 2007). 
Alguns pontos devem ser destacados em relação à economia, nesse período. Parcela importante da taxa de investimento era realizada pelo governo tanto em infraestrutura como em diversos setores produtivos estruturantes (siderurgia, mineração, petróleo e química, entre outros).

A reforma tributária e as demais mudanças institucionais de meados dos anos de 1960 definiram um esquema de financiamento da economia que viabilizou o crescimento dos investimentos do setor público e uma série de incentivos ao investimento do setor privado. A carga tributária ${ }^{2}$ permaneceu relativamente estável, sem inibir os investimentos e a poupança do setor privado, além de contribuir para a constituição de poupança do setor público. Vale destacar que a grande expansão dos anos de 1970 se fez também com o recurso ao endividamento externo, cuja reversão nas condições de financiamento externo seria o principal determinante do esgotamento do crescimento.

Esse crescimento, liderado pela indústria, possibilitou uma maior aproximação dos níveis de renda médio do Brasil ao dos países desenvolvidos e, pelo fato de o país apresentar taxas de crescimento superiores ao crescimento mundial, a participação do Brasil no PIB mundial foi se elevando. Até 1980, o crescimento brasileiro situou-se sempre acima da média mundial.

A partir de 1980, verifica-se uma forte queda nas taxas de crescimento econômico do país. De 1980 a 2011, a média de crescimento do PIB foi da ordem de 2,6\%a.a.. A reversão do crescimento está associada a um processo de crise da dívida externa, que levou a um grande esforço de transferência de recursos ao exterior, e crise fiscal decorrente do aumento do endividamento do Estado no período anterior, para contribuir com as elevadas taxas de investimento.

Esses problemas resultaram em uma forte redução da capacidade de crescimento da economia, em função da necessidade de realizar o ajuste externo e fiscal e da deterioração do ambiente macroeconômico. Fato marcante foi a profunda aceleração inflacionária iniciada a partir do final dos anos de 1970 e que foi resultar no quadro de quase hiperinflação no final dos anos de 1980 e início dos anos de 1990. As diversas políticas, para lidar tanto com o ajustamento externo como com o combate à inflação e o ajuste fiscal, resultaram em profunda perda de dinamismo econômico e eficiência.

A instabilidade econômica resultou em queda nas taxas de investimento, a queda da poupança pública levou à queda do investimento público, com significativos impactos nos setores de infraestrutura, a volatilidade do crescimento e a elevada inflação encurtaram os prazos da economia, entre outros aspectos que levaram à perda de dinamismo econômico e deterioração do ambiente de negócios.

O setor mais afetado foi o da indústria de transformação, que passou a apresentar taxas de crescimento inferiores às do PIB. Pode-se verificar no gráfico a seguir que, enquanto no período de maior crescimento econômico a média de expansão da indústria de transformação situava-se acima da média da economia, a partir dos anos de 1980 essa situação se reverteu e não mudou desde então. Com isso, a indústria de transformação vem perdendo participação 2 A carga tributária situou-se na faixa dos $15 \%$ do PIB até 1964 e se elevou para um patamar de $25 \%$ do PIB nos anos de 1970. 
no PIB de forma contínua.

Gráfico 2 - Taxa de Crescimento do PIB e PIB Ind. Transf. \%a.a. - Média Decenal Últimos 10 anos

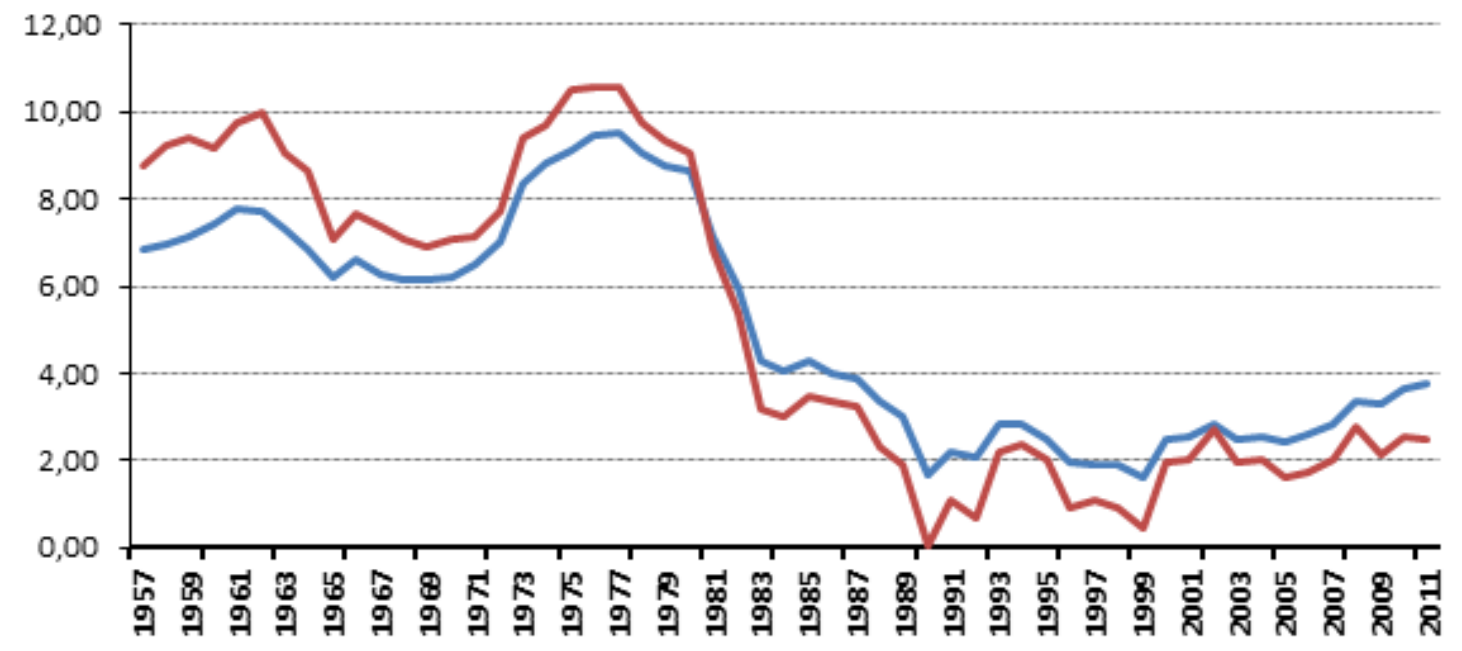

—Média Móvel Decenal PIB \%a.a. Média Móvel Decenal PIB Ind Transf \%a.a.

Pode-se verificar que o pior momento da economia foi a década de 1980, quando o crescimento médio do PIB foi de apenas 1,67\% a.a., frente a $8,67 \%$ a.a., na década anterior, e o da indústria de transformação foi de 0,03\%a.a., frente a 9,05\% a.a., nos anos de 1970. Em 5 anos, no período 1981/90, a indústria de transformação teve crescimento negativo.

Nos anos de 1990, começa-se a verificar uma melhora, com pequena elevação das taxas de crescimento, mas ainda assim muito baixo. Essa década caracteriza-se pela volta do país ao mercado financeiro internacional e pela estabilização da economia com o Plano Real em 1994.

Muitos consideravam que a queda da inflação resultaria na retomada do crescimento econômico, mas, pode-se verificar que a estabilização monetária em 1994 alterou muito pouco a situação. A taxa de crescimento média, no período de 1981/1994, foi de 1,95\% a.a. enquanto no período pós-estabilização, 1995/2011, o crescimento médio foi de 3,1\%a.a. Percebe-se que apesar da melhora, o crescimento ficou ainda bastante aquém do verificado na fase anterior da crise da dívida e muito abaixo dos outros países em desenvolvimento.

A estabilização era, portanto, condição necessária, mas não suficiente para a retomada dos investimentos, à medida que as condições macroeconômicas permaneceram desfavoráveis à atividade produtiva. A valorização da taxa de câmbio, a fragilização das contas externas, as elevadas taxas dejuros e a recorrente elevação da carga tributária, entendidos como componentes fundamentais da política de combate à inflação, geraram um ambiente perverso para a atividade econômica e, por consequência, para os investimentos produtivos. A indústria de transformação continuou sendo o setor mais penalizado nessa estratégia. Apesar de aumentar a taxa de crescimento de 0,98\%a.a. no período 1981/94 para 1,9\%a.a. entre 1995/2011, esta continuou significativamente abaixo da 
média da economia.

A taxa de crescimento foi se elevando de forma gradual, conforme se consolidava a estabilização, e de acordo com a performance da economia mundial. Isso pode ser visto pelo desempenho médio dos dois governos pósestabilização. Enquanto a média de crescimento do PIB no governo Fernando Henrique Cardoso foi de 2,31\% a.a. e da indústria de transformação de 1,2\% a.a.; no governo Lula os crescimentos foram de 3,9\% e 2,77\%a.a., respectivamente.

A partir de 2004, o crescimento econômico tornou-se mais vigoroso, com taxas médias anuais da ordem de 4,25\%. Esse processo refletiu tanto o momento favorável da economia mundial, até 2008, como a melhora de indicadores macroeconômicos do país: redução do endividamento do setor público, redução do endividamento externo, redução do risco-país, forte acúmulo de reservas internacionais. Com a crise econômica mundial de 2008, as taxas de crescimento sofreram uma retração. Nessa fase, o país voltou a apresentar taxas de crescimento ligeiramente superiores às da média mundial, revertendo a tendência de queda da participação brasileira no PIB mundial, que se verificava desde 1980. A indústria continuou a apresentar um fraco desempenho, principalmente nos anos de 2009 e 2011/12. No período 2004/11, o crescimento médio da indústria de transformação foi de 2,6\%a.a..

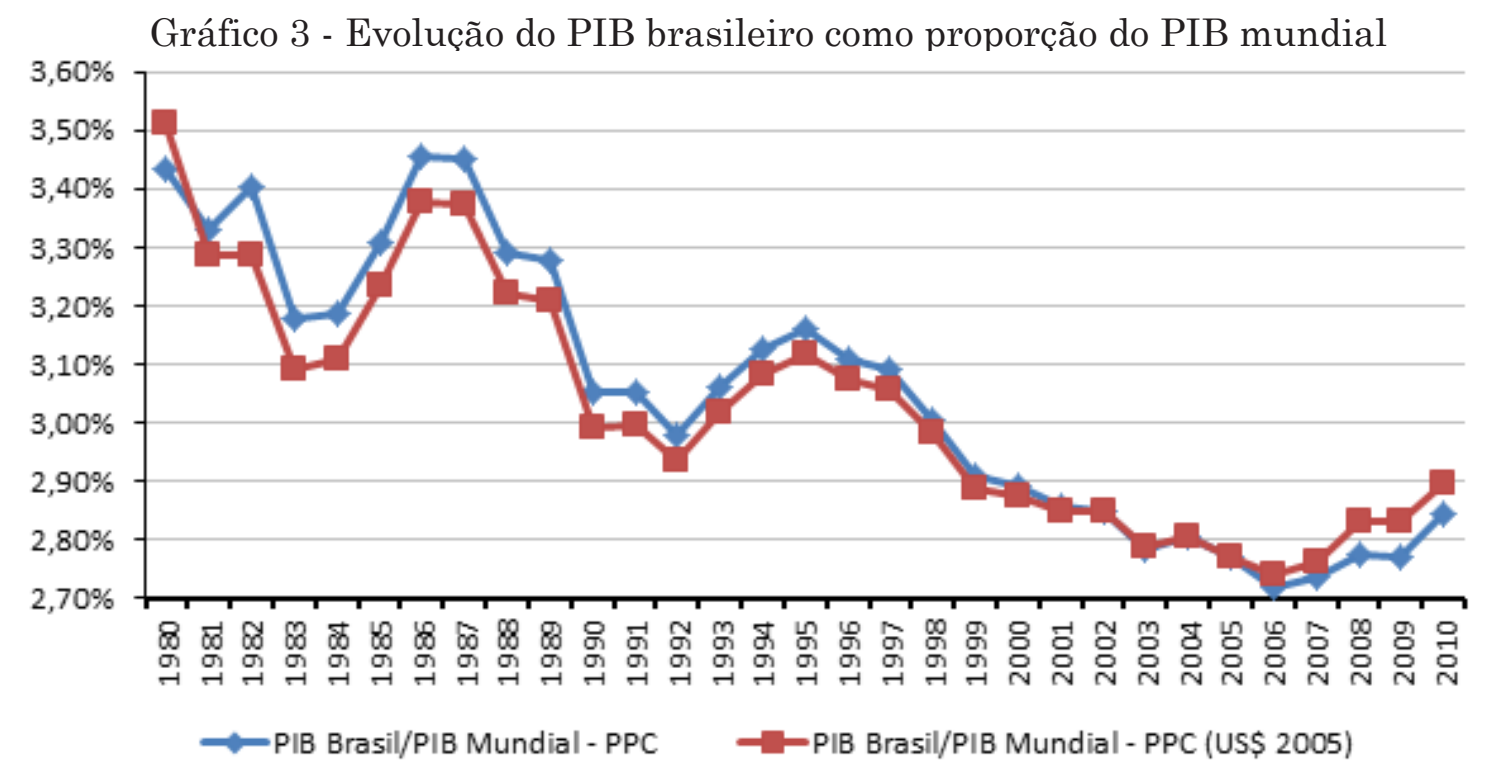

Fonte: elaboração própria a partir de dados do Banco Mundial

O pior desempenho da indústria reflete tanto o fato de a estratégia de estabilização afetá-la mais diretamente, como a dependência do crescimento da economia mundial e do preço de commodities, nas quais o país se tornou cada vez mais especializado. Um ponto importante no desempenho recente da economia brasileira foi a tendência contínua de elevação da carga tributária, a partir do patamar médio de $25 \%$ do PIB, no qual se manteve entre a reforma tributária dos anos de 1960 e 1994³. Desde então, a carga tributária vem se

\footnotetext{
3 Exceto no ano de 1990 que em função do Plano Collor a carga tributária atingiu quase 30\% do PIB, mas este foi um ano atípico com grande parte dos ganhos decorrentes de receitas extraordinárias.
} 
elevando, aproximando-se dos 35\% do PIB. Como a indústria de transformação tende a ter uma tributação superior a demais setores, esse aumento afetou, de forma mais acentuada, sua competitividade e capacidade de crescimento.

Gráfico 4 - Carga Tributária (\% PIB)

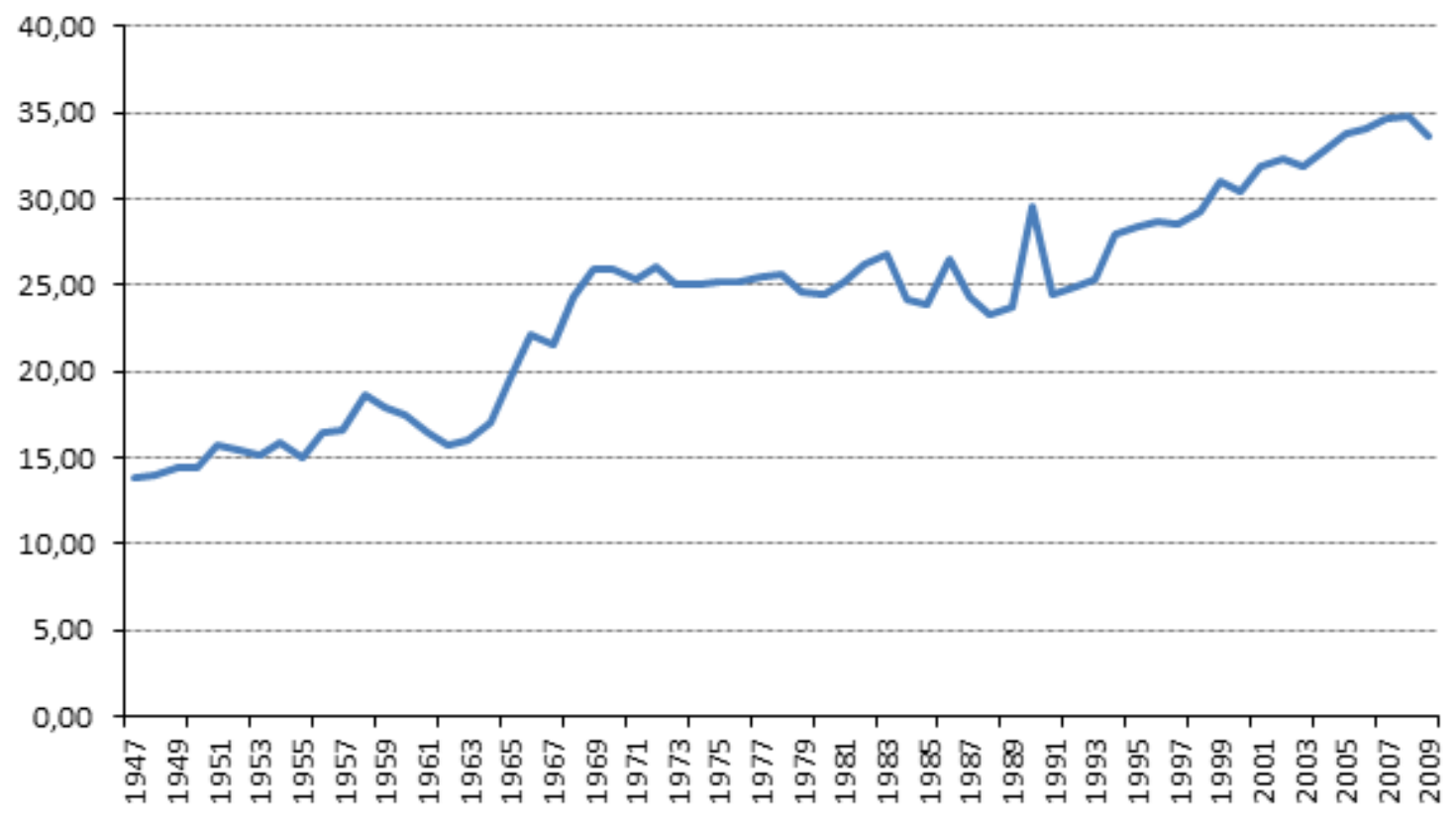

Fonte: elaboração própria a partir de dados do IPEADATA e IBGE.

Deve-se destacar que, diferentemente dos anos de 1960, quando o salto da carga tributária possibilitou o aumento da capacidade de investimento do setor público e colaborou para o bom desempenho da economia nos anos de 1970, no período recente, o seu aumento em torno de 10 pontos percentuais do PIB incrementou, quase nada, o investimento público.

O investimento total da economia começou a ter uma pequena recuperação a partir de 2007, aproximando-se, em alguns anos, da faixa dos $20 \%$ do PIB; o que ainda parece insuficiente para sustentar taxas mais elevadas de crescimento. Observando-se apenas os dados das últimas duas décadas, percebe-se que os anos em que há expansão da taxa de investimento são aqueles em que a indústria apresenta melhores performances (Gráfico 5, com dados trimestrais do período do primeiro trimestre de 1991 ao quarto trimestre de 2011), assim como os indicadores de produtividade da economia. 
Gráfico 5 - Relação entre taxa de investimento (eixo horizontal) e PIB INDÚSTRIA/PIB (eixo vertical)

$$
\text { PIB Indústria/PIB } \quad \begin{gathered}
y=0,7304 x+0,1551 \\
R^{2}=0,2451
\end{gathered}
$$

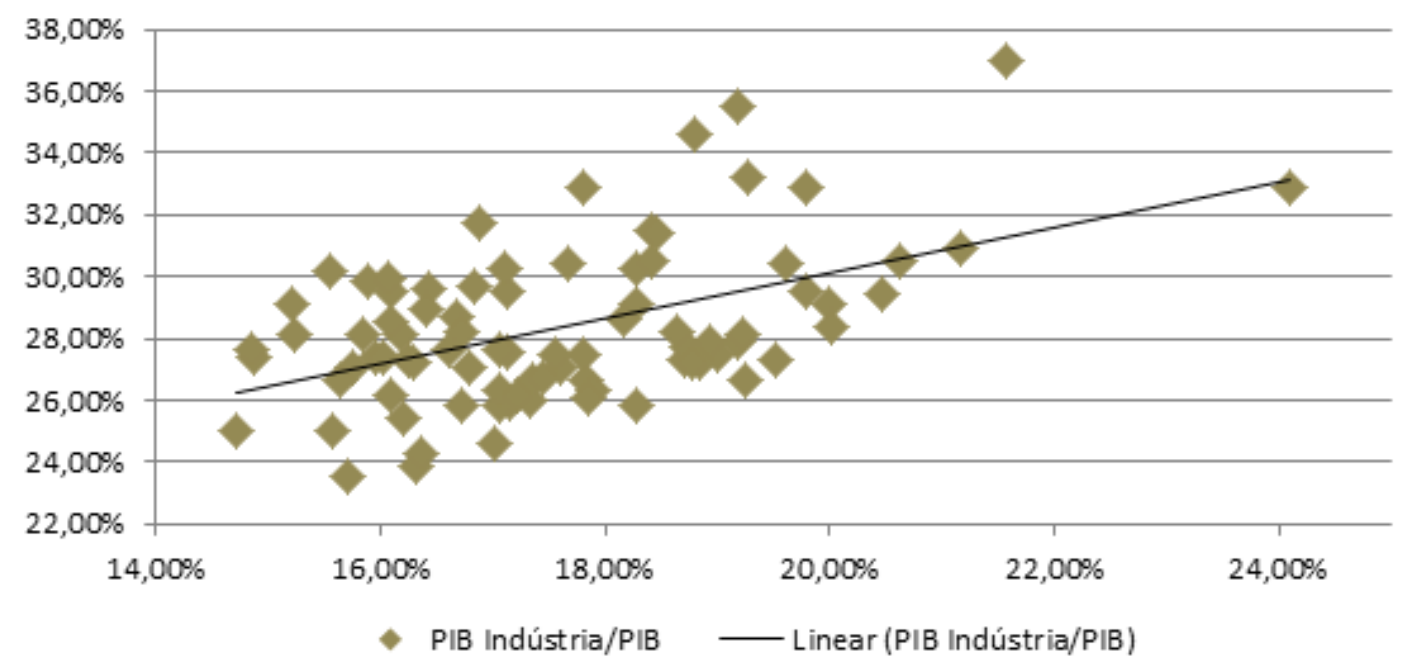

Fonte: Elaboração própria a partir de dados do IBGE.

Desse modo, existe uma relação importante entre investimento e crescimento da indústria de transformação.

\section{Considerações Finais}

A retomada do crescimento sustentável da economia, em patamares mais elevados, irá requerer avanços em todos os componentes determinantes do crescimento: acumulação de capital, capital humano e produtividade. Para estimular a elevação desses componentes, alguns pontos são de crucial importância, como a elevação da poupança pública, com redução da carga tributária, aumento do investimento público e privado na melhoria da infraestrutura e do sistema educacional. Ao se realizar essas alterações, a indústria se tornará mais competitiva, com efeitos adicionais positivos sobre o restante da economia e favorecendo um ciclo virtuoso de crescimento.

\section{Referências}

Cruz, M.J.V.; Nakabashi, L.; Porcile, G.; Scatolin, F.D. (2007). Uma análise do impacto da composição ocupacional sobre o crescimento da economia brasileira. Economia, Selecta, v. 8, n. 4, p. 55-73. 
